\title{
Finite element analysis of different configurations of fully threaded cannulated screw in the treatment of unstable femoral neck fractures
}

Jiantao $\mathrm{Li}^{1+}$, Menglin Wang ${ }^{2+}$, Lianting $\mathrm{Li}^{3+}$, Hao Zhang ${ }^{1}$, Ming Hao ${ }^{1}$, Chen $\mathrm{Li}^{4}$, Lin Han ${ }^{5}$, Jianfeng Zhou ${ }^{6 *}$ and Kun Wang ${ }^{1 *}$

\begin{abstract}
Background: In the present study, we evaluated the mechanical outcome of different configurations formed by fully threaded screws and partially threaded screws in the treatment of unstable femoral neck fracture.

Methods: The Pauwels type III unstable femoral fracture and the models of the fully threaded screw and partially threaded screw were constructed in 3-matic software and UG-NX software respectively. We then assembled the different screw configurations to the fracture model separately to form the fixation models. After meshing the models' elements, we used Abaqus software to perform the finite element analysis. Parameters of von Mises stress distribution on the screws, peak stress, displacement between fracture fragments, and model principal strains in cancellous bone were reported.

Results: Our results indicated that the peak von Mises stresses of screws was concentrated in the middle surface of the screw near the fracture line in each group. Peak stress value of the implants was highest in the model of triangle with posterior single screw. And the lowest stress values were observed in the triangular model. Fully threaded screw in each group underwent the most stress while partially threaded screw underwent a little bit of stress. Lowest displacement was observed in the triangular model. The volume of bone susceptible to yielding in the femoral neck region was the lowest for triangular configuration.
\end{abstract}

Conclusions: For unstable femoral neck fractures, superior results were obtained by stabilizing the fracture with triangular configuration formed by one superior partially threaded screw and two inferior fully threaded screws. This study will require clinical confirmation as to its practicality in the management of unstable femoral fractures.

Keywords: Unstable femoral neck fractures, Finite element analysis, Fully threaded cannulated screws, Partially threaded cannulated screws

\section{Background}

Femoral neck fractures are relatively common which account for almost $50 \%$ of all hip fractures [1]. The treatment recommendations vary depending on the fracture pattern and the patient's age [2]. Partially threaded cannulated screws (PTS) have remained a standard method

\footnotetext{
* Correspondence: wind_027@163.com; wklanhai@126.com

${ }^{\dagger}$ Jiantao Li, Menglin Wang and Lianting Li contributed equally to this work.

${ }^{6}$ Department of Emergency, Chinese PLA General Hospital, No. 28 Fuxing

Road, Beijing 100853, People's Republic of China

'Department of Orthopaedics, Chinese PLA General Hospital, No. 28 Fuxing

Road, Beijing 100853, People's Republic of China

Full list of author information is available at the end of the article
}

for the fixation of femoral neck fractures in young patients for many years $[3,4]$. The principle for this fixation technique is to enable healing by controlled fragment impaction across parallel placed screws and avoid nonunion or osteonecrosis caused by fracture gap [5]. However, loss of reduction after fixation by three PTSs of femoral neck fractures is reported to be up to $39 \%$ within the first three postoperative months [6].

Recently, fully threaded cannulated screws (FTS) have been raised regarding alternative ways for the fixation of femoral neck fractures and got the satisfied radiographic results and clinical outcome $[7,8]$. But the optimal

(C) The Author(s). 2018 Open Access This article is distributed under the terms of the Creative Commons Attribution 4.0 International License (http://creativecommons.org/licenses/by/4.0/), which permits unrestricted use, distribution, and 


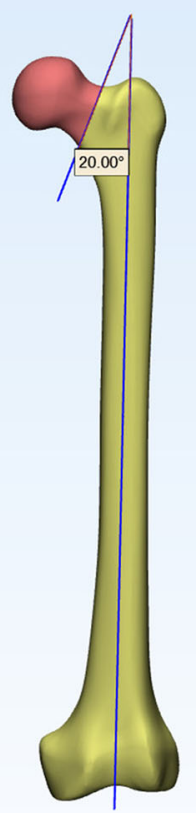

A

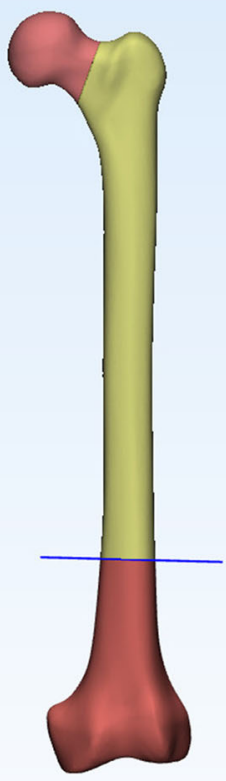

B

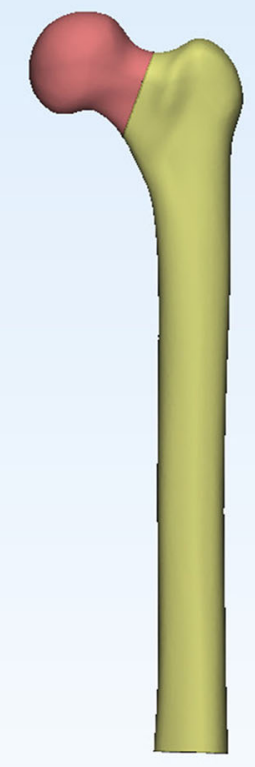

Fig. 1 a A cutting plane across the center of the femoral neck at an angle of $20^{\circ}$ with respect to the sagittal plane of the shaft axis was created. b A distal osteotomy plane was made $10 \mathrm{~cm}$ above the condyles of the femur. c The osteotomy model was created

configuration of the screws is necessary to be investigated in order to guide the clinical practice. To our best knowledge, there are not any mechanical studies of finite element analysis test being published to compare the mechanical stability of the different configurations of screws as fixation methods used in unstable femoral neck fractures. Therefore, in an effort to shed more light on this issue, we design this research to evaluate the mechanical strength of the different FTS patterns in the treatment of unstable femoral neck fractures.

\section{Methods}

The geometric model of the femur was employed from a three-dimensional model of a left fourth-generation composite femur (MODEL3405\#, Pacific Research Laboratories,
Vashon, WA). Then, we constructed the fracture model in 3-matic (Materialize, Belgian) to simulate the Pauwels type III unstable fracture [9]. We first created the femoral shaft axis, a cross which a sagittal plane was created. Then, we created a cutting plate that was across the center of the femoral neck at an angle of $20^{\circ}$ with respect to the sagittal plane of the shaft axis. The femoral neck was cut by the cutting plane, simulating a Pauwels type III fracture (Fig. 1a). And a plane was made $10 \mathrm{~cm}$ above the condyles of the femur, which was the distal osteotomy plane (Fig. 1b). The osteotomy model was created (Fig. 1c).

According to the manufacturer-provided engineering drawing, we reconstructed the geometric 3-D models of PTS (6.5 mm diameter and $16 \mathrm{~mm}$ thread length) and FTS (6.5 $\mathrm{mm}$ diameter and fully thread length) using the 
computer-aided design (CAD) software of Unigraphics NX 8.5 (Siemens PLM Software) (Fig. 2). The assemblage of the internal fixations and bones was accomplished in 3-matic to simulate the triangular configuration, inverted

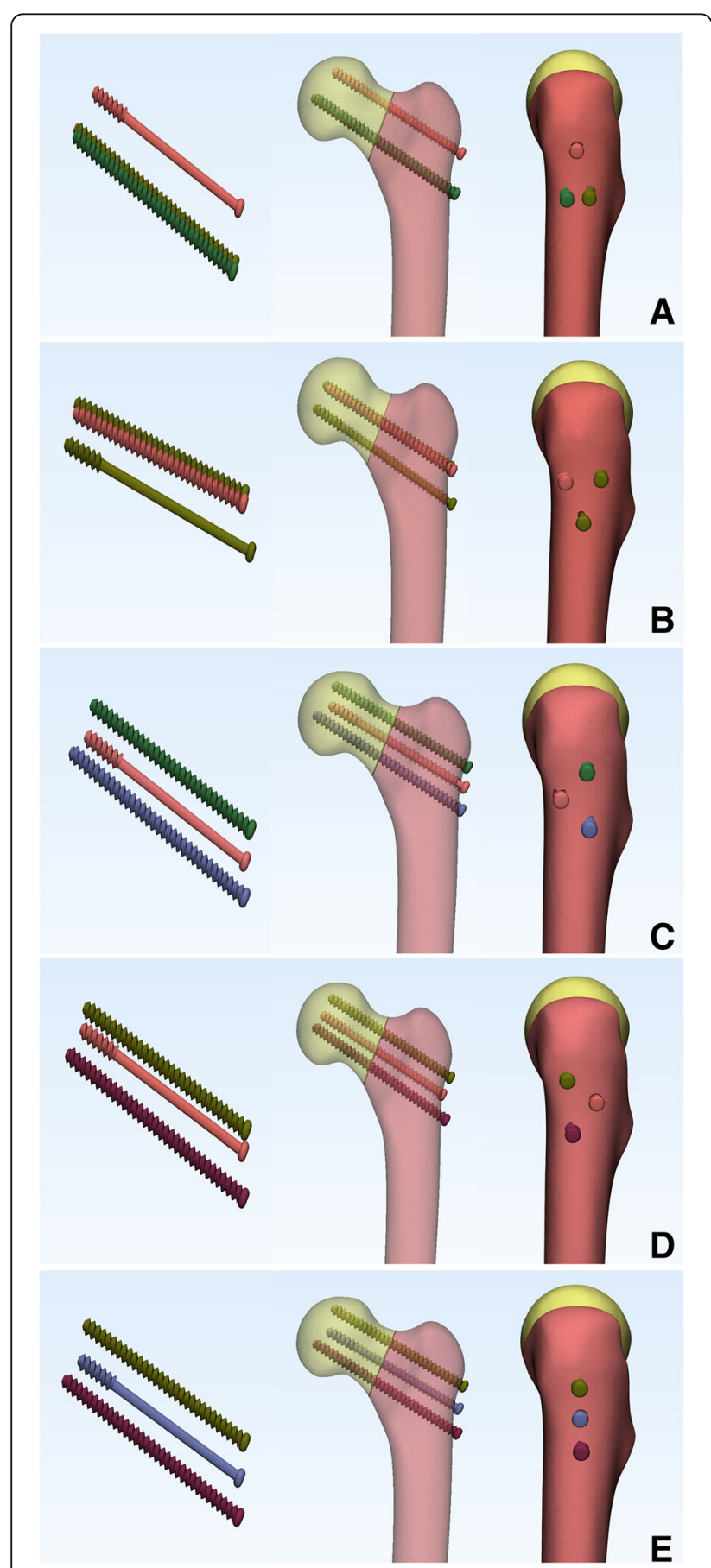

Fig. 3 Assemblage of the screws and bones was accomplished in 3matic to triangular configuration (a), inverted triangular configuration (b), triangle with anterior single screw (c), triangle with posterior single screw (d) and vertical configuration (e) triangular configuration, triangle with anterior single screw, triangle with posterior single screw, and vertical configuration (Fig. 3). Fracture models were fixed by three parallel cannulated screws, out of which two were FTSs, one was PTS. The threaded tunnels left by screws were simulated through the boolean operation in 3-matic. All the models were meshed using the software HyperMesh 11.0 (Altair Engineering, Inc., USA).

The assembled 3D models were then imported into Abaqus (Simulia, France) to generate the finite element models. The bone model was assumed to be homogeneous, isotropic with linear elastic properties as reported by the manufacturer and previous studies [10-12]. Convergence tests were performed on triangular configuration models to ensure a fine enough element discretization for displacement analysis. The modulus of elasticity and the Poisson's ratio were shown in Table 1 . The screws were made of titanium alloy (Table 1). Tetrahedral 10-node elements (C3D10) were applied to the finite element models.

Frictional contact interactions were assumed between the different parts of the models. The threaded surfaces of screws were considered to be tie constraints (bone bonded to the screw). The interfaces between bone and PTS body were simulated by contact pairs with a friction factor of 0.3 [13]. Friction coefficients for bone-bone interaction was 0.46 [14]. All nodes on the surface of distal femur were constrained with 0 degrees of freedom to prevent rigid body motions during the analysis.

This study simulated the forces loading on the hip during the stance phase of walking. The FE models were applied a load (the force vector pointed laterally at an angle of $13^{\circ}$ with the axis of the femoral shaft on the coronal plane, posteriorly by an angle of $8^{\circ}$ with the shaft in the sagittal plane) of $2100 \mathrm{~N}$ corresponding to $300 \%$ body weight, and the force was introduced to the center of the femoral head [15]. In the analysis process, all forces applied to the proximal femur were divided into four steps to simulate the weight bearing process from partially to totally. Parameters of von Mises stress distribution on the screws, peak stress, displacement between fracture fragments, and model principal strains in cancellous bone were reported. A principal strain of $0.9 \%$ was taken as the yield strain value above which bone was susceptible to yielding in accordance with previously published data [16]. Regions characterized by strains

Table 1 Material properties used in the current study (titanium alloy, cortical, and cancellous bone)

\begin{tabular}{|c|c|c|c|c|c|}
\hline \multicolumn{2}{|c|}{ Titanium alloy } & \multicolumn{2}{|c|}{ Cortical bone } & \multicolumn{2}{|c|}{ Cancellous bone } \\
\hline $\mathrm{E}(\mathrm{GPa})$ & Poisson's ratio & $\mathrm{E}(\mathrm{GPa})$ & Poisson's ratio & $\mathrm{E}(\mathrm{GPa})$ & Poisson's ratio \\
\hline 105 & 0.35 & 16.8 & 0.3 & 0.84 & 0.2 \\
\hline
\end{tabular}


Table 2 The details of models in this study

\begin{tabular}{|c|c|c|c|c|c|}
\hline & Triangle & Inverted triangle & $\begin{array}{l}\text { Triangle with anterior } \\
\text { single screw }\end{array}$ & $\begin{array}{l}\text { Triangle with posterior } \\
\text { single screw }\end{array}$ & Vertical \\
\hline \multicolumn{6}{|l|}{ Femur } \\
\hline Elements & 788,416 & 742,684 & 777,827 & 752,670 & 759,762 \\
\hline Nodes & 161,809 & 152,348 & 159,510 & 154,261 & 155,471 \\
\hline Mesh size & \multicolumn{5}{|c|}{ Maximum: 3 mm; minimum: 0.5 mm } \\
\hline \multicolumn{6}{|l|}{ PTS } \\
\hline Elements & 56,737 & 55,998 & 55,655 & 56,435 & 57,067 \\
\hline Nodes & 101,995 & 100,341 & 99,884 & 100,885 & 101,736 \\
\hline Mesh size & $1 \mathrm{~mm}$ & & & & \\
\hline \multicolumn{6}{|l|}{ FTS } \\
\hline Elements & 56,587 & 55,006 & 55,417 & 55,496 & 55,877 \\
\hline Nodes & 101,756 & 98,673 & 99,370 & 99,481 & 100,004 \\
\hline Mesh size & $1 \mathrm{~mm}$ & & & & \\
\hline
\end{tabular}

larger than this value were assigned orange and red color to emphasize regions where bone tended to be susceptible to yielding.

\section{Results}

The simulated thickness of the cortical bone in this study was $6 \mathrm{~mm}$. The number of elements and nodes of the models was listed in Table 2.

\section{Von Mises stress distribution}

Differences of stress distribution were observed on the five configurations. Stresses appeared to be concentrated in the middle surface of the screw near the fracture line of each group (Fig. 4). Peak stress value of the implants was highest in the model of triangle with posterior single screw. And the lowest stress values were observed in the triangular model (Fig. 5). FTS in each group underwent the most stress while PTS underwent a little bit of stress (Table 3 and Fig. 6).

\section{The displacement between fracture fragments}

Differences of fragment displacement were observed on the five configurations. Interfragmentary motions were calculated as the displacements between the two nodes on the proximal end of the fracture gap at the coronal view. Lowest displacement values were observed in the triangular model (Fig. 7).

\section{Maximum principal strains in the proximal fragment}

Contour plots showing maximum principal strains in cancellous bone with a cross section through the femoral neck were shown in Fig. 8. This figure is based on the assumption that failure of screw cut-out from the head is likely to occur due to high strains in the weak region of the bone structure. The volume of cancellous bone in the proximal fragment with maximum principal strains above yield strain value of $0.9 \%$ was shown in Fig. 9 .

\section{Discussion}

In the present study, we investigated the mechanical distinction of different configurations combined by PTS

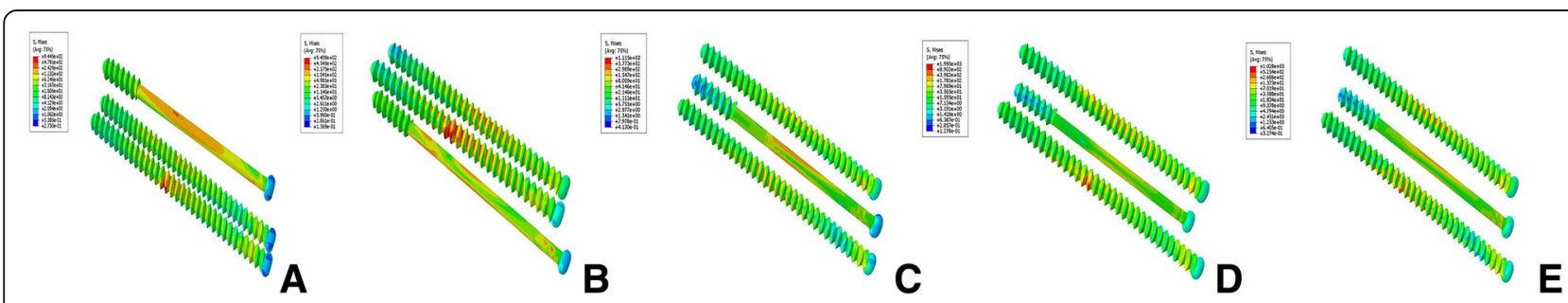

Fig. 4 Stress distribution in five fixation configurations. a Triangular model. b Inverted triangular model. c Triangle with anterior single screw. d Triangle with posterior single screw. e Vertical model. Stresses appeared to be concentrated in the middle surface of the screw near the fracture line of each group 


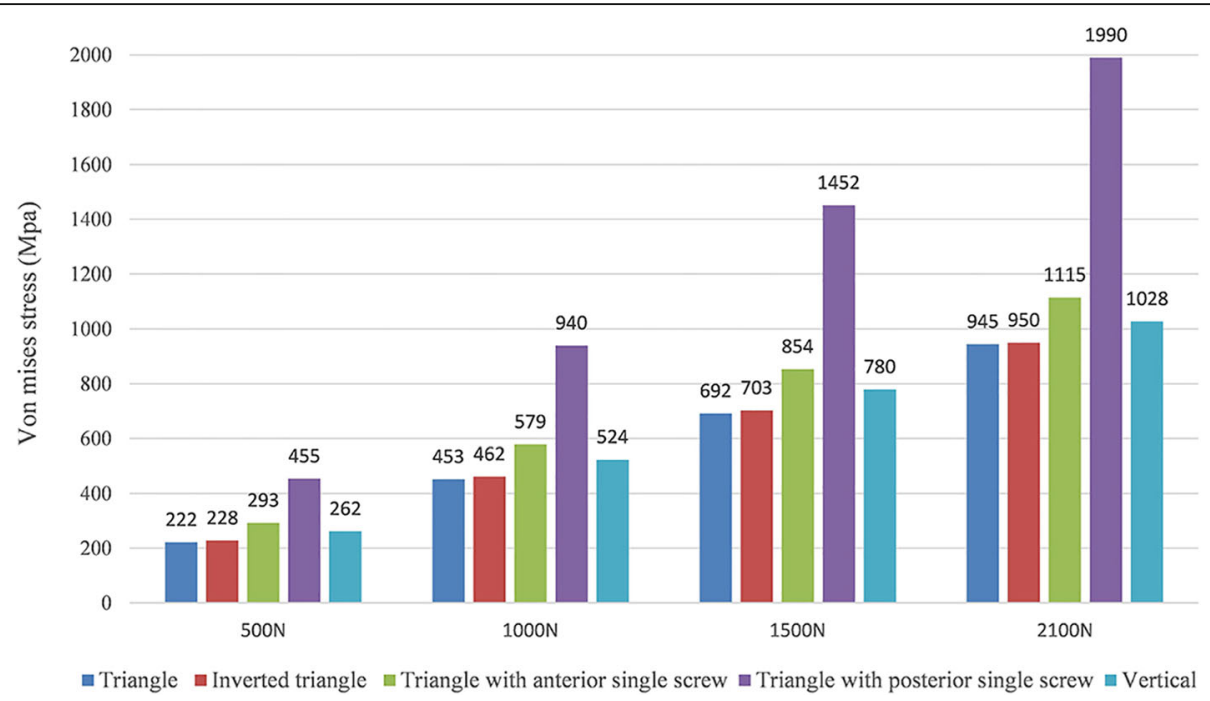

Fig. 5 Graphic demonstration of the peak stress in five configurations under the increasing loads

and FTS in the treatment of unstable femoral neck fractures using the method of finite element analysis. This study demonstrated that triangular configuration formed by one superior PTSs and two inferior FTSs underwent lowest stress value, lowest displacement of fracture gap, and minimum yielding strains in the bone when compared to other configurations. Breakage of the inferior FTS in posterior configuration model may be more likely than other models. And configuration of anterior triangle and vertical screws may tend to have a risk of cut-out.

Several studies have compared the use of different PTS configurations for the fixation of femoral neck fractures $[3,17-20]$, but few have been published to compare the mechanical stability of the different screws configurations used in the unstable femoral neck fractures. Schaefer et al. [21] demonstrated that replacing the posterior PTS with a FTS in femoral neck fracture with posterior comminution showed a potential benefit compared with the three PTS fixation models. Zhang et al. [7] concluded that using the triangle configuration of a PTS plus two headless FTSs improved the outcome of unstable femoral neck fracture patients compared to those using PTS alone clinically and biomechanically. And Weil et al. [8] demonstrated a significantly decreased rate for femoral neck shortening after cannulated screw fixation when FTSs of inverted triangular configuration were used compared to PTSs. And the mechanical results of this present study can provide some guidance to its application in clinical practice. As shown in Figs. 4 and 5, under the axial loading, triangular screws underwent the lowest stress when compared with other four configurations. This can be explained by the fact that the triangular screws provide a better anchorage than other fixation types, thereby carry lower loads. Figure 7 illustrated that the triangular screws construct provided the greatest stability to the fracture fragment since the minimum displacement of the fragment gap was achieved in the triangular configuration under the increasing loads. As to unstable femoral neck fractures, with higher shear angle and greater shear force, postoperative complications like fixation failure,

Table 3 Maximum stress (Mpa) on each screw of different models under increasing loads

\begin{tabular}{|c|c|c|c|c|c|c|c|c|c|c|c|c|c|c|c|}
\hline & \multicolumn{3}{|c|}{ Triangle } & \multicolumn{3}{|c|}{ Inverted Triangle } & \multicolumn{3}{|c|}{ Triangle with anterior single screw } & \multicolumn{3}{|c|}{ Triangle with posterior single screw } & \multicolumn{3}{|c|}{ Vertical } \\
\hline & $\overline{S^{*}}$ & IP & IA & $\overline{\mathrm{SP}}$ & SA & $1^{*}$ & $\mathrm{~S}$ & $A^{*}$ & I & $S$ & $P^{*}$ & I & $S$ & $M^{*}$ & I \\
\hline$\overline{500 \mathrm{~N}}$ & 63 & 202 & 222 & 146 & 228 & 100 & 147 & 75 & 293 & 146 & 43 & 455 & 138 & 54 & 262 \\
\hline $1000 \mathrm{~N}$ & 128 & 427 & 453 & 301 & 462 & 194 & 302 & 153 & 579 & 299 & 91 & 940 & 283 & 109 & 524 \\
\hline $1500 \mathrm{~N}$ & 195 & 676 & 692 & 464 & 703 & 284 & 466 & 231 & 854 & 460 & 142 & 1452 & 435 & 165 & 780 \\
\hline $2100 \mathrm{~N}$ & 263 & 945 & 941 & 635 & 950 & 369 & 637 & 311 & 1115 & 629 & 195 & 1990 & 593 & 223 & 1028 \\
\hline
\end{tabular}

$S$ superior, IP inferoposterior, IA inferoanterior, SP superoposterior, $S A$ superoanterior, $I$ inferior, $A$ anterior, $P$ posterior, $M$ middle

*Partially threaded cannulated screw 


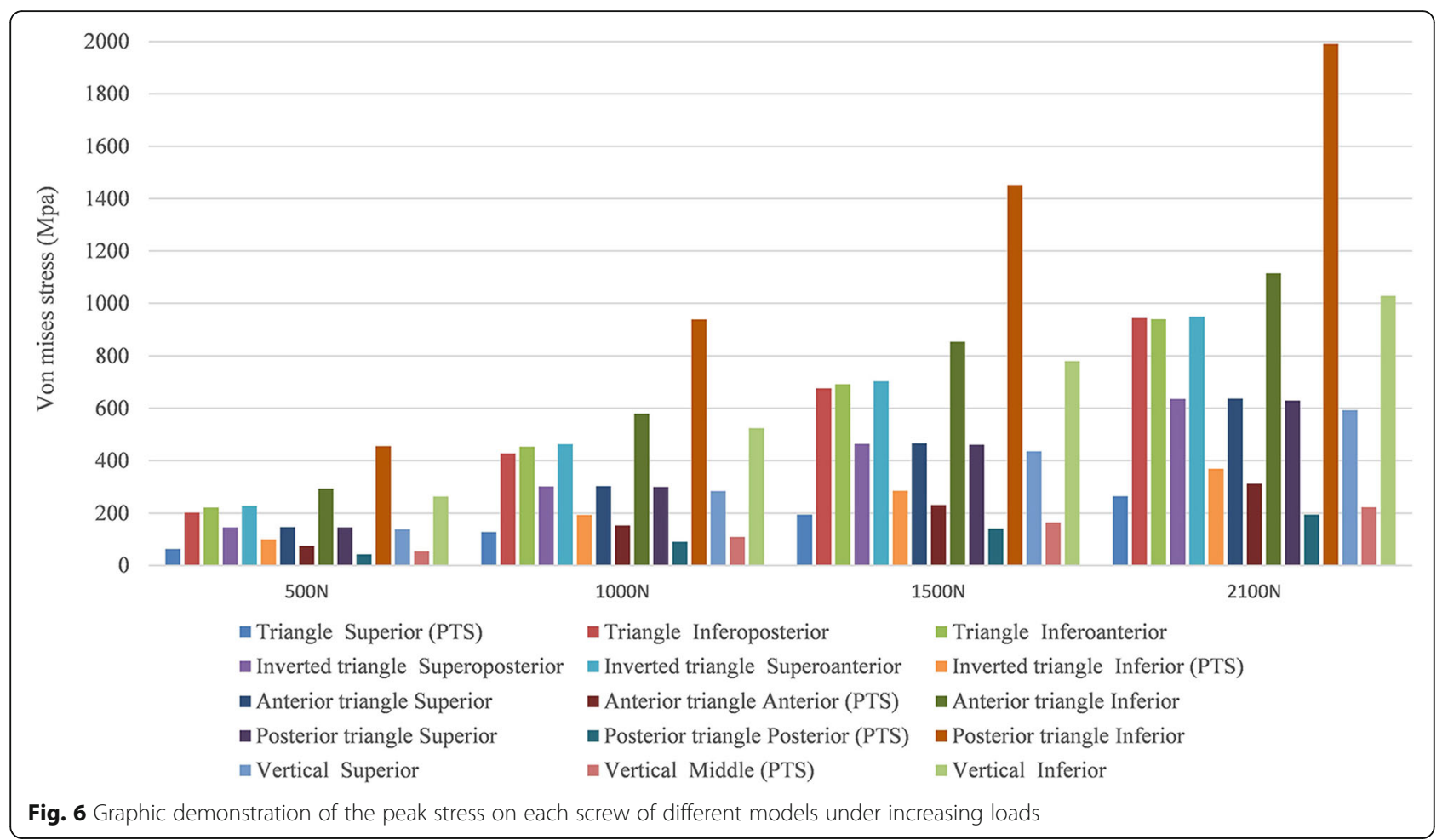

nonunion, and avascular necrosis were with high incidence [22, 23]. Heightened stability could improve femoral head blood flow leading to a decrease in avascular necrosis and union complications and was the better option in the treatment of the displaced femoral neck fractures [24]. Figures 8 and 9 showed the volume of the bone susceptible to yielding in the femoral head region, which indicated that the anchorage of the triangular screws was less likely to be involved in cut-out and was more stable. The stability of the screws within the head depends on an adequate anchorage in bone structure.

PTS has been introduced for the treatment of femoral neck fractures for many years, with advantages of less tissue invasiveness, less blood loss, shorter hospital stay, and shorter operation time $[3,25]$. However, the vertical

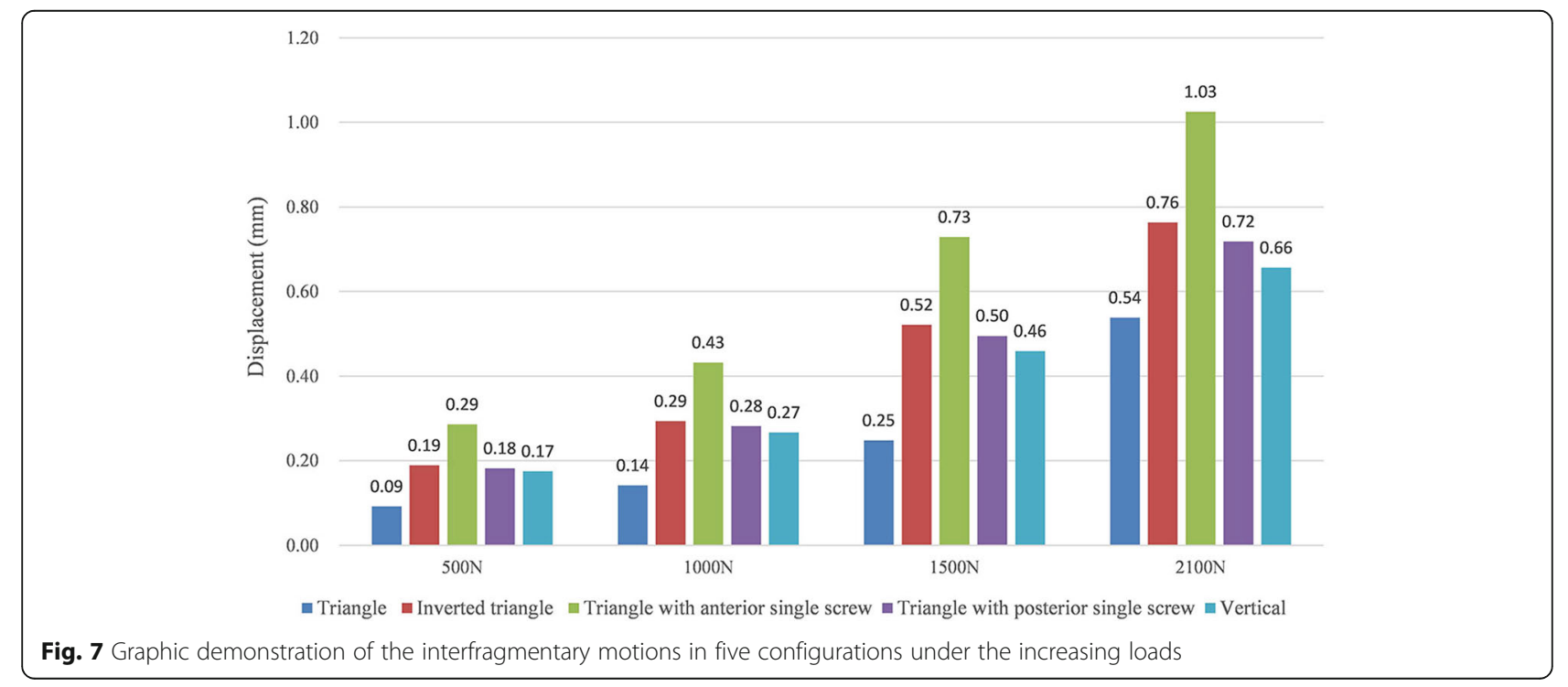




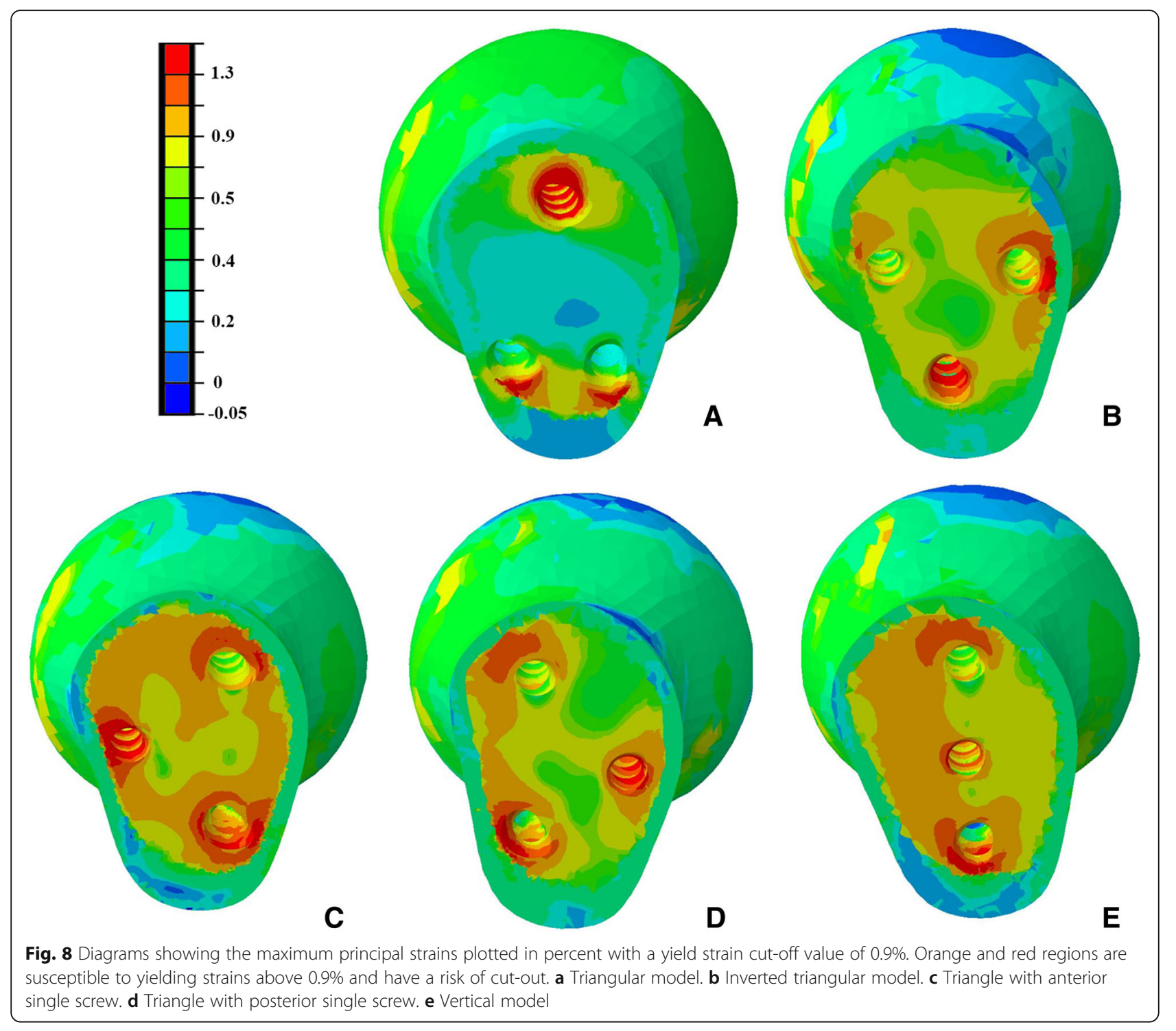

femoral neck fractures with a higher "shear angle" are so unstable that they have a higher rate of fixation failure and nonunion. The part-thread design of PTS made it obtain infinite pull strength by countering against the fragment, but with increasing the rate of screw withdrawal in the vertical fracture. And the full-thread design of FTS made it obtain more stable support to counter against the shear force of the vertical fracture, but without any pull strength to hold the fragment. The combination of the two types of screw used in the vertical femoral fractures could work. Difference mechanism made the PTS and FTS disperse different stresses. As shown in Table 3 and Fig. 6, the FTS in each group underwent the most stress while PTS underwent a little bit of stress. In the present study, we tended to use one PTS to provide the fragment compression and prevent gapping. And the function of two FTSs was to maintain the fracture reduction and resist the shear force. The results of finite element analysis indicated that the triangular configuration showed mechanical advantage compared with the other configurations.

No experimental validation was conducted, which clearly is a limitation. However, our aim was to examine trends rather than absolute values. In this respect, the lack of experimental validation is justified. A previous experimentally validated numerical study [10-12] employed the same loading and boundary conditions as our study. And more real biomechanical tests and clinical trials are needed to overcome the limitations of our study. Despite these limitations, this study is the first finite element analysis study to compare the mechanical efficiency of five different configurations combined by PTS and FTS for the treatment of 


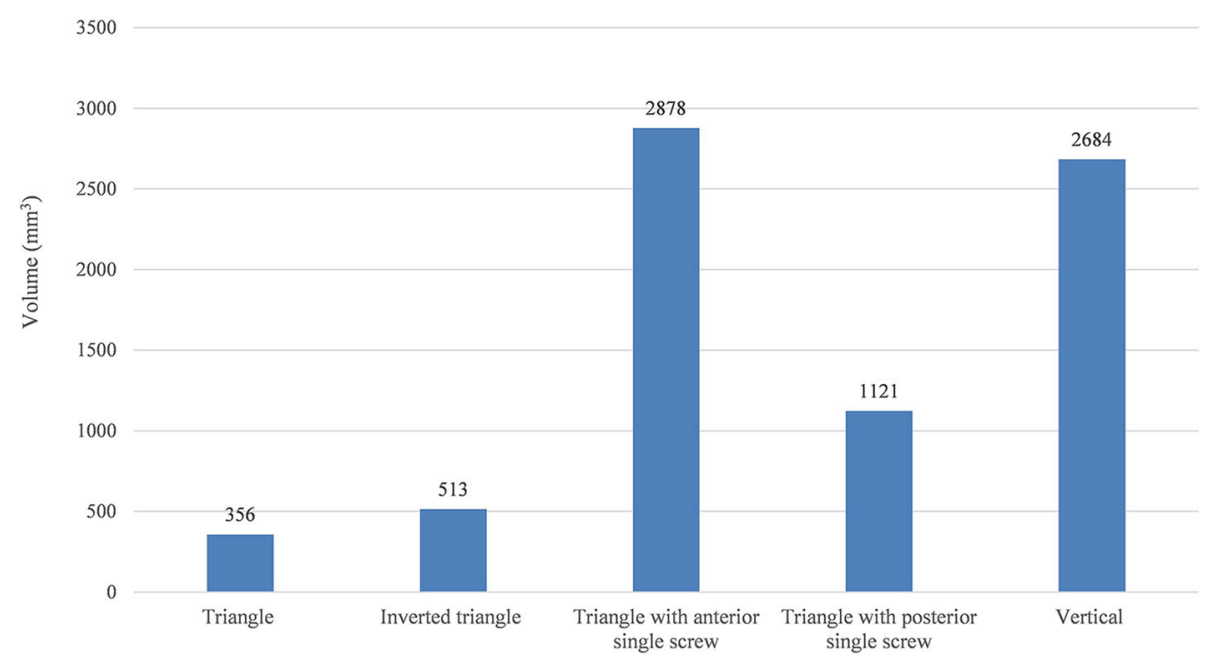

Fig. 9 Volume of cancellous bone in the proximal fragment with maximum principal strains above yield strain value of $0.9 \%$

unstable femoral neck fractures. Besides, we also simulated threaded tunnels of every screw in our models, with the mesh refinement around the areas which brought the parameter level to a more realistic value.

\section{Conclusions}

In conclusion, the mechanical behaviors of five different screw configurations used to stabilize unstable femoral neck fractures were compared using finite element analysis. For unstable femoral neck fractures, superior results were obtained by stabilizing the fracture with triangular configuration formed by one superior PTS and two inferior FTSs when compared with other configurations of two FTSs and one PTS. This study will require clinical confirmation as to its practicality in the management of unstable femoral fractures.

\section{Abbreviations}

CAD: Computer-aided design; FTS: Fully threaded cannulated screw; PTS: Partially threaded cannulated screw

\section{Acknowledgements}

Not applicable

\section{Funding}

This study was not supported by any fundings.

\section{Availability of data and materials}

All of the data are available in contact with the correspondent author.

\section{Authors' contributions}

$J \mathrm{~L}, \mathrm{MW}$, and $\mathrm{KW}$ conceived the study and wrote the manuscript. $L L$ and $J Z$ reconstructed the models and performed the finite element analysis. $\mathrm{HZ}$, $\mathrm{MH}, \mathrm{CL}$, and $\mathrm{LH}$ contributed to the data collection and interpretation of the results. All authors read and approved the final manuscript and consented to publish this manuscript.

Ethics approval and consent to participate Not applicable
Consent for publication

Not applicable

\section{Competing interests}

The authors declare that they have no competing interests.

\section{Publisher's Note}

Springer Nature remains neutral with regard to jurisdictional claims in published maps and institutional affiliations.

\section{Author details}

'Department of Orthopaedics, Chinese PLA General Hospital, No. 28 Fuxing Road, Beijing 100853, People's Republic of China. 'Department of Otolaryngology Head and Neck Surgery, Peking University Third Hospital, Beijing 100191, People's Republic of China. ${ }^{3}$ Department of Orthopaedics, The Third People's Hospital of Qingdao, No. 29 Yongping Road, Qingdao 266041, People's Republic of China. ${ }^{4}$ Department of Orthopaedics, Tianjin Hospital, NO. 406 Jiefang Road, Tianjin 300211, People's Republic of China. ${ }^{5}$ Graduate School of the Second Military Medical University, Shanghai 200433, China. ${ }^{6}$ Department of Emergency, Chinese PLA General Hospital, No. 28 Fuxing Road, Beijing 100853, People's Republic of China.

Received: 21 July 2018 Accepted: 11 October 2018 Published online: 29 October 2018

\section{References}

1. Støen R, Nordsletten L, Meyer H, Frihagen J, Falch J, et al. Hip fracture incidence is decreasing in the high incidence area of Oslo, Norway. Osteoporos Int. 2012;23:2527-34.

2. Lowe JA, Crist BD, Bhandari M, Ferguson TA. Optimal treatment of femoral neck fractures according to patient's physiologic age: an evidence-based review. Orthop Clin North Am. 2010;41:157-66.

3. Selvan VT, Oakley MJ, Rangan A, Al-Lami MK. Optimum configuration of cannulated hip screws for the fixation of intracapsular hip fractures: a biomechanical study. Injury. 2004;35:136-41.

4. Yang JJ, Lin LC, Chao KH, Chuang SY, Wu CC, et al. Risk factors for nonunion in patients with intracapsular femoral neck fractures treated with three cannulated screws placed in either a triangle or an inverted triangle configuration. J Bone Joint Surg Am. 2013;95:61-9.

5. Parker MJ, Porter KM, Eastwood DM, Schembi Wismayer M, Bernard AA. Intracapsular fractures of the neck of femur. Parallel or crossed garden screws? The J Bone Joint Surgery Br. 1991;73:826-7.

6. Gurusamy K, Parker MJ, Rowlands TK. The complications of displaced intracapsular fractures of the hip: the effect of screw positioning and angulation on fracture healing. J Bone Joint Surgery Br. 2005;87:632-4. 
7. Zhang B, Liu J, Zhu Y, Zhang W. A new configuration of cannulated screw fixation in the treatment of vertical femoral neck fractures. Int Orthop. 2018; 42:1949-55.

8. Weil YA, Qawasmi F, Liebergall M, Mosheiff R, Khoury A. Use of fully threaded cannulated screws decreases femoral neck shortening after fixation of femoral neck fractures. Arch Orthop Trauma Surg. 2018;138:661-7.

9. Rupprecht M, Grossterlinden L, Ruecker AH, de Oliveira AN, Sellenschloh K et al. A comparative biomechanical analysis of fixation devices for unstable femoral neck fractures: the Intertan versus cannulated screws or a dynamic hip screw. J Trauma. 2011;71:625-34.

10. Gardner MP, Chong AC, Pollock AG, Wooley PH. Mechanical evaluation of large-size fourth-generation composite femur and tibia models. Ann Biomed Eng. 2010:38:613-20.

11. Grassi L, Väänänen S, Amin Yavari S, Weinans H, Jurvelin J, et al. Experimental validation of finite element model for proximal composite femur using optical measurements. J Mech Behav Biomed Mater. 2013;21:86-94.

12. Heiner A. Structural properties of fourth-generation composite femurs and tibias. J Biomech. 2008;41:3282-4.

13. Eberle $\mathrm{S}$, Gerber $\mathrm{C}$, Von Oldenburg G, Högel F, Augat P. A biomechanical evaluation of orthopaedic implants for hip fractures by finite element analysis and in-vitro tests. Proc Inst Mech Eng H J Eng Med. 2010;224:1141-52.

14. Chen WP, Tai CL, Shih CH, Hsieh PH, Leou MC, et al. Selection of fixation devices in proximal femur rotational osteotomy: clinical complications and finite element analysis. Clin Biomech (Bristol, Avon). 2004;19:255-62.

15. Goffin JM, Pankaj P, Simpson AH. The importance of lag screw position for the stabilization of trochanteric fractures with a sliding hip screw: a subjectspecific finite element study. J Orthop Res. 2013;31:596-600.

16. Goffin J, Pankaj P, Simpson A, Seil R, Gerich T. Does bone compaction around the helical blade of a proximal femoral nail anti-rotation (PFNA) decrease the risk of cut-out? A subject-specific computational study. Bone Joint Res. 2013;2:79-83.

17. Alho A, Austdal S, Benterud JG, Blikra G, Lerud P, et al. Biases in a randomized comparison of three types of screw fixation in displaced femoral neck fractures. Acta Orthop Scand. 1998;69:463-8.

18. Lagerby M, Asplund S, Ringqvist I. Cannulated screws for fixation of femoral neck fractures. No difference between Uppsala screws and Richards screws in a randomized prospective study of 268 cases. Acta Orthop Scand. 1998:69:387-91.

19. Benterud J, Husby T, Graadahl O, Alho A. Implant holding power of the femoral head. A cadaver study of fracture screws. Acta Orthop Scand. 1992;63:47-9

20. Crowell R Pull out strength of fixation devices in trabecular bone of the femoral head. 1985

21. Schaefer TK, Spross C, Stoffel KK, Yates PJ. Biomechanical properties of a posterior fully threaded positioning screw for cannulated screw fixation of displaced neck of femur fractures. Injury. 2015;46:2130-3.

22. Guimaraes JAM, Rocha LR, Noronha Rocha TH, Bonfim DC, da Costa RS, et al. Vertical femoral neck fractures in young adults: a closed fixation strategy using a transverse cancellous lag screw. Injury. 2017;48(Suppl 4):S10-s16.

23. Zlowodzki M, Ayeni O, Petrisor BA, Bhandari M. Femoral neck shortening after fracture fixation with multiple cancellous screws: incidence and effect on function. J Trauma. 2008;64:163-9.

24. Szita J, Cserhati P, Bosch U, Manninger J, Bodzay T, et al. Intracapsular femoral neck fractures: the importance of early reduction and stable osteosynthesis. Injury. 2002;33(Suppl 3):C41-6.

25. Warschawski Y, Sharfman ZT, Berger O, Steinberg EL, Amar E, et al. Dynamic locking plate vs. simple cannulated screws for nondisplaced intracapsular hip fracture: A comparative study. Injury. 2016:47:424-7.

Ready to submit your research? Choose BMC and benefit from:

- fast, convenient online submission

- thorough peer review by experienced researchers in your field

- rapid publication on acceptance

- support for research data, including large and complex data types

- gold Open Access which fosters wider collaboration and increased citations

- maximum visibility for your research: over $100 \mathrm{M}$ website views per year

At $\mathrm{BMC}$, research is always in progress.

Learn more biomedcentral.com/submissions 